\title{
The Newton Raphson Method in the Extraction of Parameters of PV Modules
}

\author{
L. R. D. Reis, J. R. Camacho, D. F. Novacki.
}

\author{
School of Electrical Engineering \\ Universidade Federal de Uberlândia (UFU) \\ Campus Santa Mônica- Av. João Naves de Ávila, 2121. ZipCode:38400.902 - Uberlândia - MG - Brazil \\ Phone: +55 343239 4734, email: laizrocha16@gmail.com, jrcamacho@ufu.br, deborafalnov@gmail.com.
}

\begin{abstract}
This research is justified by the expansion of electrical systems and the large-scale adoption of small electric power generation systems, in this particular case the semiconductor photovoltaic $(P V)$ systems connected to the grid. In order to analyse these systems it is imperative that the parameters of these generation systems are of reasonable reliability. This research aims to study mathematical methods to obtain parameters of photovoltaic modules for static and dynamic studies in medium voltage electrical energy systems. Therefore, it is necessary to use equations that characterize this generation system, depending on the parameters of interest. These model parameters are: generated photo current, reverse saturation current, ideality factor, series resistance and parallel resistance. These parameters are of fundamental importance for the simulation of this generation system and the reconstruction of V.I and P.V curves of photovoltaic systems in power systems. Other genetic algorithm methods have already been used in this research in the past to obtain these parameters when totally unknown [1], [2]. The Newton Raphson method is a mathematical method widely used in power systems and can be used when one has a rough idea of the solution. This article clearly shows the possibility of using this fast method.
\end{abstract}

Keywords. Parameters extraction, Newton Raphson Method, Photovoltaic Module, Modeling.

\section{Introduction}

Among all renewable energy sources, the most abundant is solar energy. This energy reaches the earth through the solar rays, which are electromagnetic waves that carry light and heat necessary for terrestrial life.

The conversion of solar energy into electrical energy occurs through the solar irradiation that reaches the surface of the earth. The energy transformation can be harnessed through two different types of power plants: (i) photovoltaic, which consists of the arrangement of photovoltaic modules installed in a relatively large area, usually made of semiconductors (silicon, germanim, etc...), capable of converting solar irradiation directly into electricity; And (ii) heliothermic, which consists of the generation of electricity through the heating of a fluid and will function in a similar way to a conventional thermoelectric plant [3]. Among the two types of solar power plants, photovoltaic systems have proved to be more viable and therefore more competitive.

The efficiency of photovoltaic systems is influenced by three questions: the efficiency of the photovoltaic module, which depends on the way it is made, the materials used and the constructive aspects of the converter used, and lastly the efficiency of the algorithm, which controls and traces the point of maximum power for the system, the maximum power point tracking (MPPT) algorithm.

Improving the efficiency of the module and the converter is a more labor-intensive task, which requires research and development by the manufacturers, however, improving the efficiency of the MPPT algorithm is easier and cheaper [4].

To work on the development and improvement of the control algorithm it is necessary to first extract the parameters of the module or the photovoltaic system that one wishes to work. Therefore, this article aims to obtain a method that is able to extract such parameters through traditional fast numerical methods applied to engineering problems, able to characterize the behavior of the module in working conditions.

The extraction of parameters of a photovoltaic module has already been studied by another researcher at the Center of Research and Extension in Alternative Energies (NUPEA). Although, the research developed in this case used a genetic algorithm based method, the Trust-Region Optimization Method [1], [2], since the parameters were completely unknown.

\section{PV Module Modelling}

Some technical characteristics of the photovoltaic module are provided by the manufacturer, they are: The open circuit voltage $\mathrm{V}_{\mathrm{OC}}$, obtained from the measurement of voltage in the module when it has no load; the current of the module when the device is shorted ISC (short circuit current) and the maximum power $\left(\mathrm{P}_{\mathrm{MP}}\right)$ of a photovoltaic 
module, reached when are obtained the maximum power current $\left(\mathrm{I}_{\mathrm{MP}}\right)$ and the maximum power voltage $\left(\mathrm{V}_{\mathrm{MP}}\right)[5]$, illustrated in Figure 1.

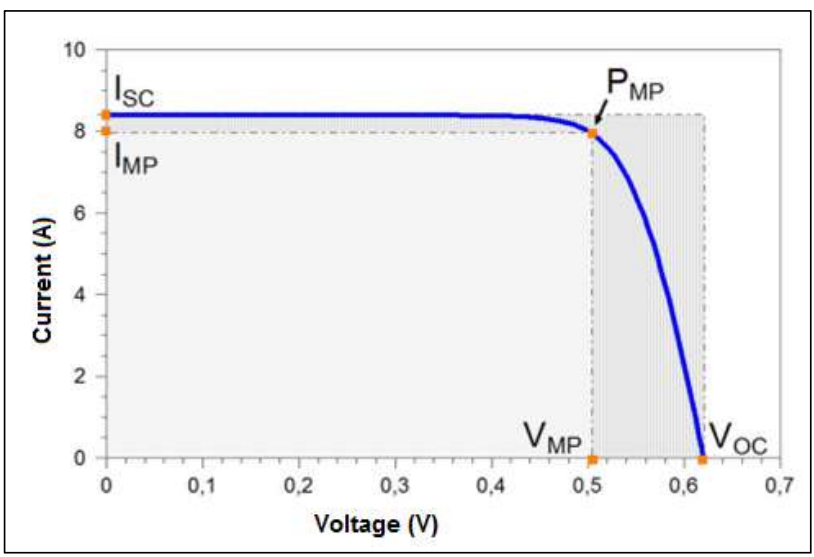

Fig, 1: Tipical V-I curve of a PV cell[6].

\section{A. Equivalent Circuit of a Cell Photovoltaics: Single Diode Model}

A photovoltaic cell is simply a P-N junction semiconductor. When exposed to sunlight, a current is generated and varies proportionally to the irradiance at that time [7]. Figure 2 below shows the equivalent circuit of a photovoltaic cell with one diode.

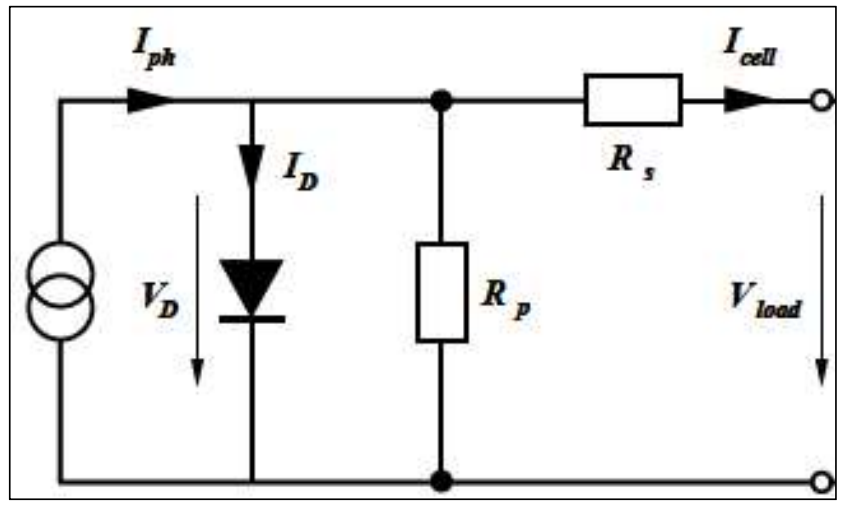

Fig. 2: Equivalent circuit $f$ a PV cell with one diode [8].

Equation describing the circuit is given by:

$$
I=I_{p h}-I_{D}\left(e^{\frac{q\left(V+I R_{s}\right)}{m K T}}-1\right)-\frac{V+I R_{s}}{R_{s h}}
$$

where:

I - cell current (A),

$\mathrm{I}_{\mathrm{ph}}$ - photo generated current $(\mathrm{A})$,

$I_{D}$ - diode reverse saturation current $(A)$,

$\mathrm{q}$ - electron elementary charge $(1,602 \times$

$10^{-19}$ coulombs),

$\mathrm{K}$ - the Boltzmann constant $\left(1,381 \times 10^{-23} \mathrm{~J} / \mathrm{K}\right)$,

$\mathrm{T}$ - cell temperature $(\mathrm{K})$,

$\mathrm{m}$ - diode ideality fator,

$\mathrm{R}_{\mathrm{S}}-$ cell series resistance $(\Omega)$,

$\mathrm{R}_{\text {sh }}$ or $\mathrm{R}_{\mathrm{p}}$ - cell shunt resistance $(\Omega)$,

$\mathrm{V}$ - cell output voltage $(\mathrm{V})$.
In the case of PV modules with various series connected cells, equation 1 become:

$$
I=I_{L}-I_{D}\left(e^{\frac{q\left(V+I R_{s}\right)}{N_{s} m K T}}-1\right)-\frac{V+I R_{s}}{R_{p}}
$$

Being $\mathrm{N}_{\mathrm{s}}$ the number of series connected cells.

The reverse saturation current of the diode ( $\mathrm{I}_{\mathrm{S}}$ ) is produced by the component when the cell is not under sunlight, i.e. it is in the dark. It depends on the local temperature and is generated thermally.

The series and parallel resistors presented are responsible for internal dissipations in the cell. The series resistance $\left(R_{S}\right)$ originates in the resistance of the semiconductor material itself, in the metal contacts and in metal-semiconductor junctions, characterizes the material's ohmic losses, the series resistance contributes to reduce the $\mathrm{I}_{\mathrm{sc}}$ of the cell, but practically does not affect its $\mathrm{V}_{\mathrm{oc}}$.

The parallel resistance $\left(\mathrm{R}_{\mathrm{sh}}\right)$ is caused by impurities and defects in the structure, especially near the edges, which produce an internal path for a leakage current, thus reducing the current effectively produced by the device, so $R_{\text {sh }}$ consists of reducing $V_{O C}$ without influence in $I_{S C}$ [6].

\section{The Newton Raphson Method}

The Newton Raphson Method is an iterative method that consists in estimate of a given function $f(x)$ with an initial guess.

The method is obtained through the Taylor series expansion in $\left(\boldsymbol{x}-\boldsymbol{x}_{\mathbf{0}}\right)$ given below.

$$
f(x)=f\left(x_{0}\right)+f^{\prime}\left(x_{0}\right)\left(x-x_{0}\right)+\frac{1}{2} f^{\prime \prime}\left(x_{0}\right)\left(x-x_{0}\right)^{2}+\ldots=0
$$

Suppose the initial guess is very close to the real root of the equation. Then $\left(x-x_{0}\right)$ is small enough and only the first terms are important for estimating the value of the root, given $\mathrm{x}_{0}$. By truncating the series in the second term we obtain the general formula of Newton Raphson's method [9].

$$
x_{1}=x_{0}-\frac{f\left(x_{0}\right)}{f^{\prime}\left(x_{0}\right)}
$$

Therefore, given $x_{n}$, the point $x_{(n+1)}$ will be obtained by intersecting the tangent line at $f(x)$ in $x_{n}$ with the $x$ axis. You can illustrate this mathematically, according to equation (3) and graphically, according to figure (3).

$$
x_{n+1}=x_{n}-\frac{f\left(x_{n}\right)}{f^{\prime}\left(x_{n}\right)}
$$




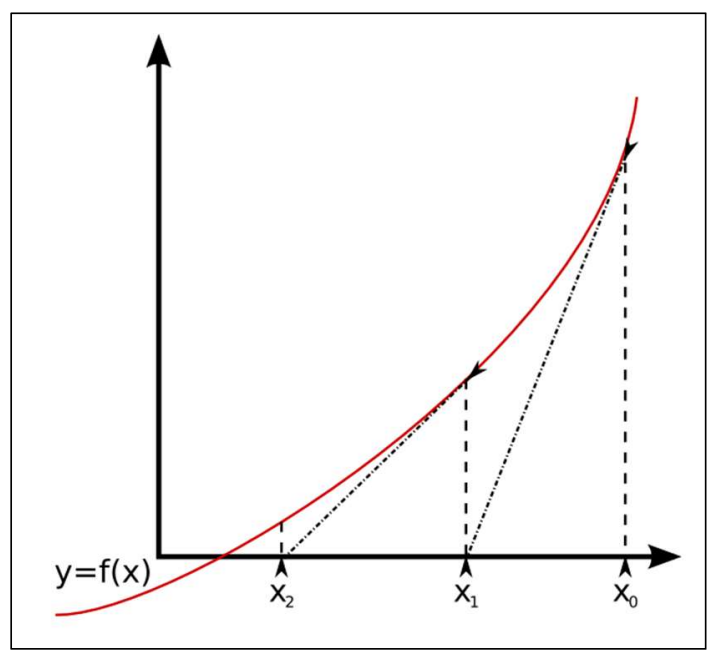

Figure 3: Illustration of the Newton Raphson Method.

The convergence of the Newton Raphson Method is guaranteed for a certain interval $[a, b]$ containing the root of $f(x)$, provided that $f(x)$ and $f^{\prime}(x)$ are continuous in this interval and that $f(\alpha)=0$, where $\alpha$ is the root of $f(x)[10]$.

\section{Problem Formulation}

The data were obtained through measurements performed on a photovoltaic module. The technical characteristics of the module used are shown in Table I.

\begin{tabular}{l} 
Table I. - Feature of the PV Module \\
\cline { 2 - 2 } \multicolumn{1}{c|}{} \\
\begin{tabular}{|c|c|}
\hline Power & Value \\
\hline$V_{m p}$ & $40 \mathrm{~W}$ \\
\hline$I_{m p}$ & $16.6 \mathrm{~V}$ \\
\hline $\mathrm{V}_{\mathrm{oc}}$ & $2.45 \mathrm{~A}$ \\
\hline $\mathrm{I}_{\mathrm{SC}}$ & $20.5 \mathrm{~V}$ \\
\hline $\mathrm{N}_{\mathrm{s}}$ & $2.80 \mathrm{~A}$ \\
\hline Material Type & 36 \\
\hline
\end{tabular}
\end{tabular}

The voltage and current curves of the photovoltaic module were obtained through the mini KLA meter. The meter operates with a temperature range of -20 to $100^{\circ} \mathrm{C}$ and an accuracy of $\mp 0.4 \%$. In addition, the meter provides the internal temperature of the module and the solar irradiance to which it is subjected.

Two tests were carried out with the same photovoltaic module at different times. The data of the two curves obtained are shown in Table II.

\begin{tabular}{|c|c|c|}
\hline & Irradiance & Temperature \\
\hline Curve 1 & $225 \mathrm{~W} / \mathrm{m}^{2}$ & $25^{\circ} \mathrm{C}$ \\
\hline Curve 2 & $596.8 \mathrm{~W} / \mathrm{m}^{2}$ & $35^{\circ} \mathrm{C}$ \\
\hline
\end{tabular}

With the knowledge of data to obtain the curves, a program was developed in the Octave computational tool to generate the two curves, according to the figures below. Figures four and six show the relationship of voltage and current obtained, highlighting the five points used in the developed program. Figures 5 and 7 illustrate the relationship of voltage and power, highlighting the point of maximum power.

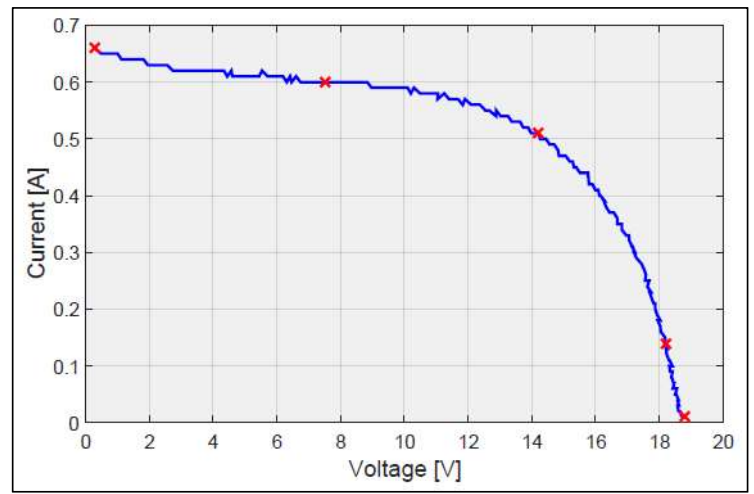

Fig. 4: Curve 1 - Relationship of voltage and current.

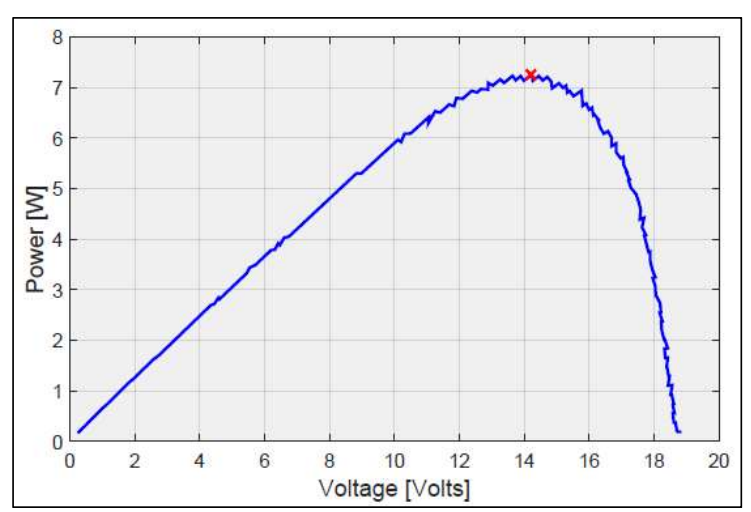

Fig. 5: Curve 1-Relationship of voltage and power.

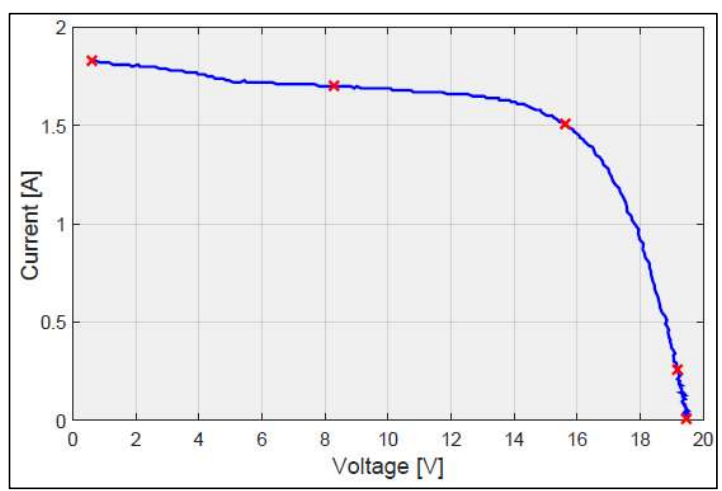

Fig. 6: Curve 2 - Relationship of voltage and current

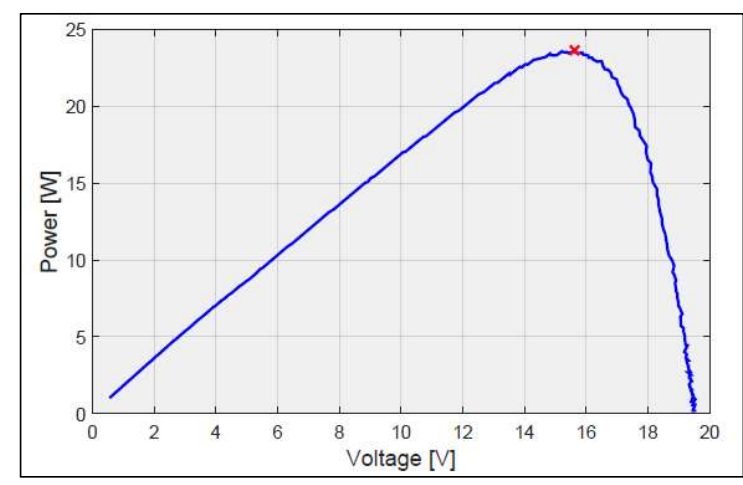

Fig. 7: Curve 2 - Relationship of voltage and power.

In order to apply the Newton Raphson numerical method to the proposed problem it is necessary to use several points of the sampled curve. In the case of a diode 
model, it is necessary to extract five parameters, and it is essential to formulate five equations so that the solution of the problem becomes possible. Therefore, it is necessary to extract from the real curve five points that will be used in solving the problem. In this work, such points were used: The first corresponds to the initial point of the curve, being $I_{l}$ near $I_{S C}$; The third corresponds to the maximum power point $P_{M P}$, with $I_{3}=I_{M P}$ and $V_{3}=V_{M P}$; The fifth being close to $V_{O C}$. The second and fourth were chosen arbitrarily, considering $\left(I_{2}, V_{2}\right)=L / 2$ and $\left(I_{4}, V_{4}\right)=3 . L / 2$, so that $L$ represents the total number of points of the real curve. The five points sampled are highlighted in $\mathrm{VxI}$ curves of figures (4) and (6). Through equation 2, it is then possible to generate the five equations used in the system, as shown below.

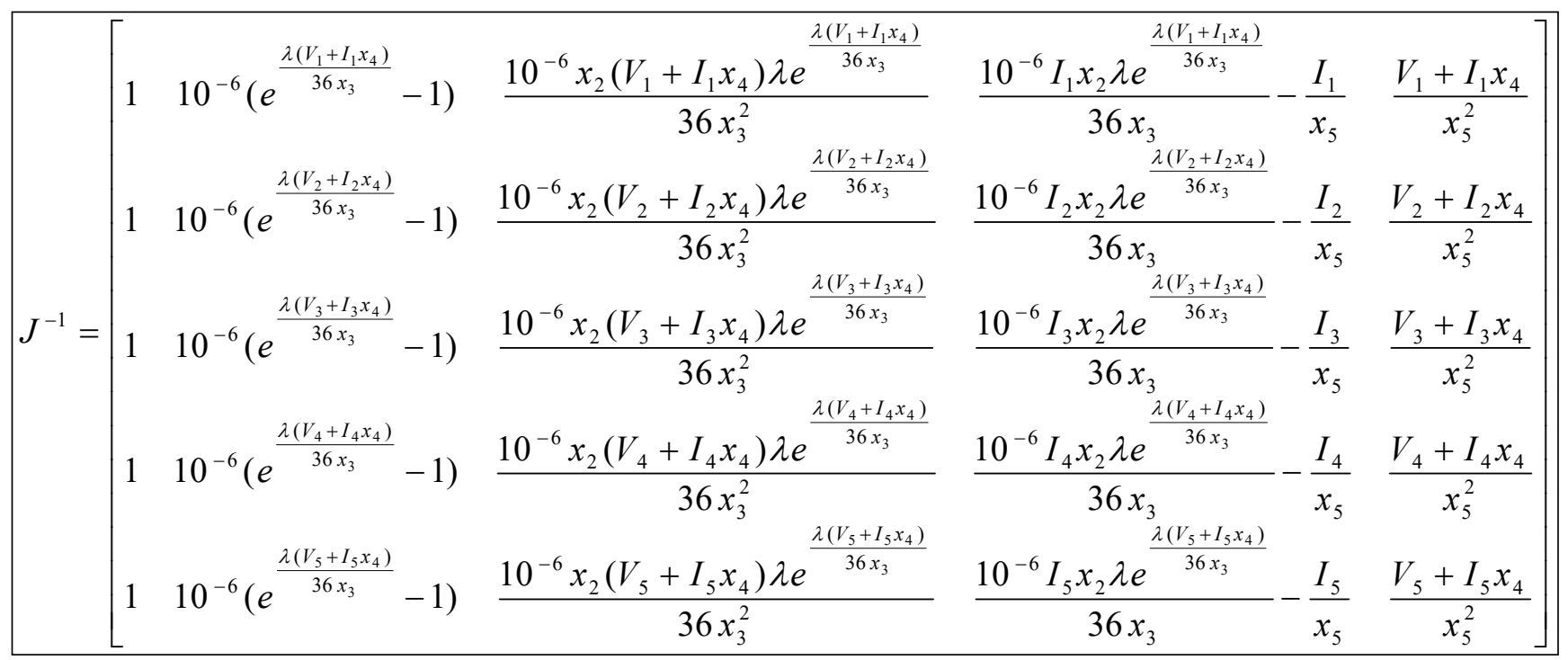

corresponds to the last sampled point of the curve, $V_{5}$

Fig. 8: Inverse of the Jacobian Matrix

$$
\begin{aligned}
& f_{1}(x)=x_{1}-10^{-6} x_{2}\left(e^{\frac{\lambda\left(V_{1}+I_{1} x_{4}\right)}{36 x_{3}}}-1\right)-\frac{\left(V_{1}+I_{1} x_{4}\right)}{x_{5}}-I_{1}=0 \\
& f_{2}(x)=x_{1}-10^{-6} x_{2}\left(e^{\frac{\lambda\left(V_{2}+I_{2} x_{4}\right)}{36 x_{3}}}-1\right)-\frac{\left(V_{2}+I_{2} x_{4}\right)}{x_{5}}-I_{2}=0 \\
& f_{3}(x)=x_{1}-10^{-6} x_{2}\left(e^{\frac{\lambda\left(V_{3}+I_{3} x_{4}\right)}{36 x_{3}}}-1\right)-\frac{\left(V_{3}+I_{3} x_{4}\right)}{x_{5}}-I_{1}=0 \\
& f_{4}(x)=x_{1}-10^{-6} x_{2}\left(e^{\frac{\lambda\left(V_{4}+I_{4} x_{4}\right)}{36 x_{3}}}-1\right)-\frac{\left(V_{4}+I_{4} x_{4}\right)}{x_{5}}-I_{4}=0 \\
& f_{5}(x)=x_{1}-10^{-6} x_{2}\left(e^{\frac{\lambda\left(V_{5}+I_{5} x_{4}\right)}{36 x_{3}}}-1\right)-\frac{\left(V_{5}+I_{5} x_{4}\right)}{x_{5}}-I_{5}=0
\end{aligned}
$$

Given the equations, it is possible to assemble the system to solve the problem.

$$
\left[\begin{array}{l}
x_{1, k+1} \\
x_{2, k+1} \\
x_{3, k+1} \\
x_{4, k+1} \\
x_{5, k+1}
\end{array}\right]=\left[\begin{array}{l}
x_{1, k} \\
x_{2, k} \\
x_{3, k} \\
x_{4, k} \\
x_{5, k}
\end{array}\right]-\left[\begin{array}{lllll}
\frac{\partial f_{1}}{x_{1}} & \frac{\partial f_{1}}{x_{2}} & \frac{\partial f_{1}}{x_{3}} & \frac{\partial f_{1}}{x_{4}} & \frac{\partial f_{1}}{x_{5}} \\
\frac{\partial f_{2}}{x_{1}} & \frac{\partial f_{2}}{x_{2}} & \frac{\partial f_{2}}{x_{3}} & \frac{\partial f_{2}}{x_{4}} & \frac{\partial f_{2}}{x_{5}} \\
\frac{\partial f_{3}}{x_{1}} & \frac{\partial f_{3}}{x_{2}} & \frac{\partial f_{3}}{x_{3}} & \frac{\partial f_{3}}{x_{4}} & \frac{\partial f_{3}}{x_{5}} \\
\frac{\partial f_{4}}{x_{1}} & \frac{\partial f_{4}}{x_{2}} & \frac{\partial f_{4}}{x_{3}} & \frac{\partial f_{4}}{x_{4}} & \frac{\partial f_{4}}{x_{5}} \\
\frac{\partial f_{5}}{x_{1}} & \frac{\partial f_{5}}{x_{2}} & \frac{\partial f_{5}}{x_{3}} & \frac{\partial f_{5}}{x_{4}} & \frac{\partial f_{5}}{x_{5}}
\end{array}\right]^{-1} \cdot\left[\begin{array}{l}
f_{1}\left(x_{k}\right) \\
f_{2}\left(x_{k}\right) \\
f_{3}\left(x_{k}\right) \\
f_{4}\left(x_{k}\right) \\
f_{5}\left(x_{k}\right)
\end{array}\right]
$$

Being the inverse of the Jacobian matrix given by Figure 8, where,

$$
\lambda=\frac{q}{T} \text { and }\left[\begin{array}{l}
x_{1} \\
x_{2} \\
x_{3} \\
x_{4} \\
x_{5}
\end{array}\right]=\left[\begin{array}{c}
I_{p h} \\
I_{d} \\
m \\
R_{s} \\
R_{s h}
\end{array}\right] .
$$

\section{Results Analysis}

After the tests made un the program developed using Octave, the following results were obtained:

Table III. - Initial Guess Used

\begin{tabular}{|c|c|}
\hline \multicolumn{2}{|c|}{ INITIAL GUESS (IG) } \\
\hline $1^{\mathrm{o}}$ & $\mathrm{x} 0=[1.5 ; 0.5 ; 1.0 ; 0.5 ; 50]$ \\
\hline $2^{\mathrm{o}}$ & $\mathrm{x} 0=[2.0 ; 0.1 ; 1.0 ; 1.0 ; 100]$ \\
\hline $3^{\mathrm{o}}$ & $\mathrm{x} 0=[2.0 ; 1.0 ; 1.0 ; 1.0 ; 100]$ \\
\hline $4^{\mathrm{o}}$ & $\mathrm{x} 0=[2.0 ; 1.0 ; 1.0 ; 1.0 ; 50]$ \\
\hline $5^{\mathrm{o}}$ & $\mathrm{x} 0=[0.6 ; 2.5 ; 1.5 ; 2.0 ; 100]$ \\
\hline
\end{tabular}

During the simulations executed several guesses were used, some of them converged to solve the problem, others did not. From those that converged, shown in Table III, it was observed that the generated values were identical. In addition, it was noted that the initial guess when closer to the root generated fewer iterations, as shown in Tables IV and V. 
Table IV. - Obtained Parameters of the Curve 1

\begin{tabular}{|c|c|c|c|c|c|c|}
\hline \multicolumn{7}{|c|}{ CURVE 1 } \\
\hline IG & Iph(A) & Is.10-6 $(\mu A)$ & m & Rs $(\Omega)$ & Rsh $(\Omega)$ & Iters \\
\hline $1^{\mathrm{o}}$ & 0.6687 & 2.006 & 1.4288 & 1.1686 & 120.58 & 9 \\
\hline $2^{\mathrm{o}}$ & 0.6687 & 2.006 & 1.4288 & 1.1686 & 120.58 & 7 \\
\hline $3^{\mathrm{o}}$ & 0.6687 & 2.006 & 1.4288 & 1.1686 & 120.58 & 9 \\
\hline $4^{\mathrm{o}}$ & 0.6687 & 2.006 & 1.4288 & 1.1686 & 120.58 & 9 \\
\hline $5^{\mathrm{o}}$ & 0.6687 & 2.006 & 1.4288 & 1.1686 & 120.58 & 4 \\
\hline
\end{tabular}

Table V. - Obtained parameters of curve 2

\begin{tabular}{|c|c|c|c|c|c|c|}
\hline \multicolumn{7}{|c|}{ CURVE 2} \\
\hline IG & Iph(A) & Is. 10-6 $(\mu \mathrm{A})$ & $\mathrm{m}$ & Rs $(\Omega)$ & Rsh $(\Omega)$ & Iters \\
\hline $1^{\text {o }}$ & 1.8462 & 0.0441 & 1.0245 & 0.1979 & 58.92 & 5 \\
\hline $2^{\text {o }}$ & 1.8462 & 0.0441 & 1.0245 & 0.1979 & 58.92 & 7 \\
\hline $3^{\text {o }}$ & 1.8462 & 0.0441 & 1.0245 & 0.1979 & 58.92 & 8 \\
\hline $4^{\text {o }}$ & 1.8462 & 0.0441 & 1.0245 & 0.1979 & 58.92 & 8 \\
\hline
\end{tabular}

With the results obtained in tables $\mathrm{V}$ and VI, it was possible to simulate the corresponding curves. Figures 9 and 10 show a relationship of current and voltage, comparing a real curve with a simulated curve. It is possible to observe that the simulated curves go through the five points used in the problem formulation, thus obtaining a good approximation of the real curve.

Figures 11 and 12 show the relation of power and voltage. It is possible to observe that the simulated curves were able to reach the points of maximum power and that their shape is close to the real curve.

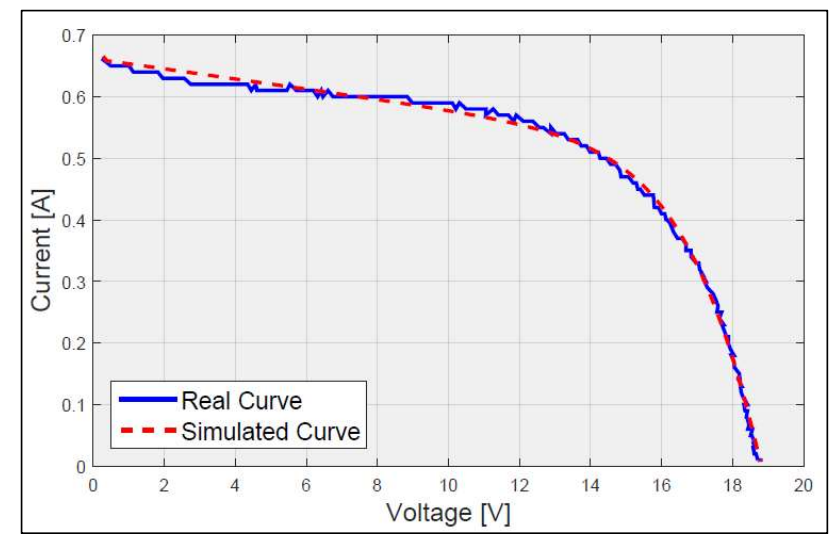

Fig. 9: Curve $\mathrm{I} x \mathrm{~V}, \mathrm{~T}=25^{\circ} \mathrm{C}$ e $\mathrm{G}=225.0 \mathrm{~W} / \mathrm{m}^{2}$.

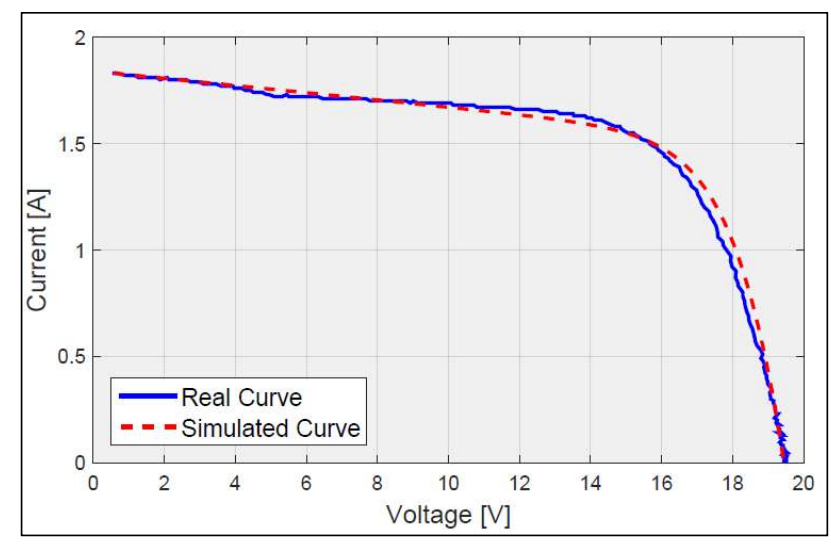

Fig. 10: Curve $\mathrm{I} x \mathrm{~V}, \mathrm{~T}=35^{\circ} \mathrm{C}$ e $\mathrm{G}=596.8 \mathrm{~W} / \mathrm{m}^{2}$.

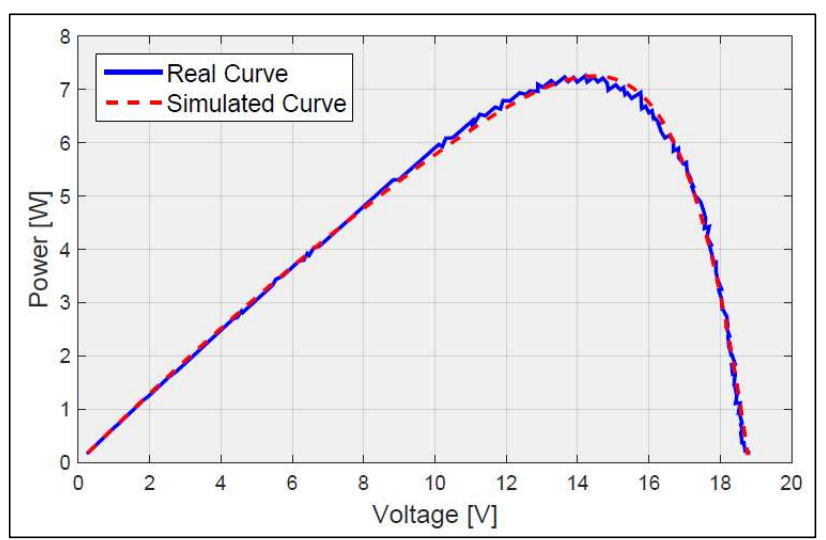

Fig. 11: Curve $\mathrm{P} \times \mathrm{V}, \mathrm{T}=25^{\circ} \mathrm{C}$ e $\mathrm{G}=225.0 \mathrm{~W} / \mathrm{m}^{2}$.

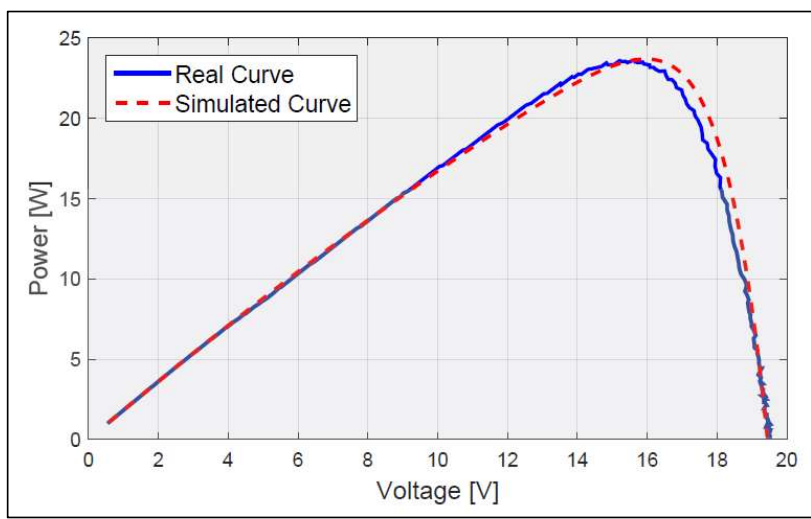

Fig. 12: Curve $\mathrm{P} \times \mathrm{V}, \mathrm{T}=35^{\circ} \mathrm{C}$ e $\mathrm{G}=596.8 \mathrm{~W} / \mathrm{m}^{2}$.

When using the Newton Raphson method, it is necessary to have a knowledge of the approximate value that one wishes to obtain, since the initial guess should be close to the solution of the problem, otherwise the method is not able to find the solution. This knowledge is necessary because, the Jacobian matrix calculated in each iteration must be nonsingular, that is, with the determinant other than zero.

The study of photovoltaic systems has evolved a lot in the last years, this has generated in the researchers of the subject an improvement of the knowledge, thus allowing to estimate values close to the real parameters of photovoltaic cells.

However, tests were performed with values distant from the solution, as an example, when the initial guess $\mathrm{n}$ curve 1 was $\mathrm{x} 0=[1.5 ; 1 \mathrm{e}-3 ; 1.5 ; 1.5 ; 100]$, and in curve 2 when $\mathrm{x} 0=[1.5 ; 1.0 ; 1.5 ; 1.5 ; 100]$, the result was not obtained because the method did not show convergence.

Comparing the results obtained in this article with those from [1], the parameters $I_{p h}$ (photogenerated current), $m$ (diode ideality factor) and $R_{s h}$ (parallel resistance) approximated to those found by that author. The parameters $I_{d}$ (diode reverse current) and $R_{s}$ (series resistance) diverged considerably, as shown in Table VI.

Table VI. - Obtained Parameters fromTrust-Region Methods [7]

\begin{tabular}{|c|c|c|c|c|c|}
\hline Curve & $\mathrm{I}_{\mathrm{ph}}(\mathrm{A})$ & $\mathrm{I}_{\mathrm{s} .10^{-6}}(\mu \mathrm{A})$ & $\mathrm{m}$ & $\mathrm{R}_{\mathrm{s}}\left({ }^{\prime} \Omega\right)$ & $\mathrm{R}_{\text {sh }}(\Omega)$ \\
\hline $1^{\mathrm{o}}$ & 0.6736 & 2.4258 & 1.3390 & 2.0364 & 129.8172 \\
\hline $2^{\mathrm{o}}$ & 1.8498 & 0.1632 & 1.0411 & 0.5282 & 69.1844 \\
\hline
\end{tabular}




\section{Conclusions}

The parameters from VxI curve using the method proposed in this work presented satisfactory results when compared to the actual curve obtained from the photovoltaic module.

The Newton Raphson method can be used for various types of problems with nonlinear equations, being able to cover several areas of science. However, it is fundamental to have the knowledge of a range of values close to the solution, otherwise convergence is not obtained, as was shown in this work.

The results found in this work approximated those obtained in [1], even using different methods, the divergences in the calculated parameters were small, allowing a comparison between the two studies.

The method is very reliable to get parameters of modules when the user has some knowledge of the PV system under investigation, and the approximated values of parameters to be used as an initial guess. The Thrust Region Method algorithm used in the past is very useful when the user has no idea on the initial guess of parameters.

Finally, this work presents a simple and fast mathematical method that can be applied in practical electrical engineering problems of photovoltaic systems.

\section{Acknowledgements}

The authors are grateful to CNPQ (Brazilian National Council for Scientific and Technological Development) for the financial support of this research and to UFU (Universidade Federal de Uberlândia) for the support and opportunity to conduct the research in this institution.

\section{References}

[1] P. Rodrigues, J. R. Camacho, and F. B. Matos "The application of Trust Region Method to estimate the parameters of photovoltaic modules through the use of single and double exponential models", in International Conference on Renewable Energies and Power Quality (ICREPQ), 2011.

[2] P. Rodrigues, "The extraction of parameter of photovoltaic panels from the solution of a non-linear equation system through thrust region techniques". MSc Dissertation. Universidade Federal de Uberlândia, Uberlândia, Minas Gerais, Brazil, 2012, 117p. (In portuguese)

[3] FGV ENERGIA. "Complementary Renewable Energies". Energy Notebooks from Fundação Getúlio Vargas. December, 2015, Year 2, $\mathrm{N}^{\circ} 4$.

[4] Shivananda Pukhrem, "A Photovoltaic Panel Model in Matlab/Simulink”, Wroclaw University of Technology (2013).

[5] R. Zilles, W. N. Macêdo, M. A. B. Galhardo and S. H. F. Oliveira, "Photovoltaic systems connected to the grid", Workshop Texts, 2012, 208p. (In portuguese)

[6] J.T. Pinho, and M.A. Galdino, "Photovoltaic Systems Engineering Manual", CEPEL-CRESESB, Rio de Janeiro (2014), 530p. (In portuguese)

[7] Jacob Jamesm Nedumgatt, Jayakrishnan K. B., Umashankar S., Vijayakumar D., "Perturb and Observe MPPT Algorithm for Solar PV Systems-Modeling and Simulation", in Proc. School of Electrical Engineering, VIT University.

[8] F. Kininger, "Photovoltaic Systems Technology", Kassel University (2003), Germany, 155p.

[9] M. D. Smith, "Newton-Raphson Technique", 1998, Electronic document available in: http://web.mit.edu/10.001/Web/Course Notes/NLAE/node6.ht ml. Accessed in October, 02, 2016.

[10] E. F. Cota, A. F. Bastos, S. R. Silva e H. A. Pereira, "Application of the Newton-Raphson Method in the Control of the External Resistance of Wind Generators During Voltage Sags", in Proc. IV SBSE (2012), Goiânia, Goiás, Brasil. (In portuguese) 